\title{
Steady state analysis of a storage integrated solar thermophotovoltaic (SISTPV) system
}

\author{
A. Datas D.L. Chubb A. Veeraragavan
}

\begin{abstract}
This paper presents the theoretical analysis of a storage integrated solar thermophotovoltaic (SISTPV) system operating in steady state. These systems combine thermophotovoltaic (TPV) technology and high temperature thermal storage phase-change materials (PCM) in the same unit, providing a great potential in terms of efficiency, cost reduction and storage energy density. The main attraction in the proposed system is its simplicity and modularity compared to conventional Concentrated Solar Power (CSP) technologies. This is mainly due to the absence of moving parts. In this paper we analyze the use of Silicon as the phase change material (PCM). Silicon is an excellent candidate because of its high melting point $(1680 \mathrm{~K})$ and its very high latent heat of fusion of $1800 \mathrm{~kJ} / \mathrm{kg}$, which is about ten times greater than the conventional PCMs like molten salts. For a simple system configuration, we have demonstrated that overall conversion efficiencies up to $\sim 35 \%$ are approachable. Although higher efficiencies are expected by incorporating more advanced devices like multijunction TPV cells, narrow band selective emitters or adopting near-field TPV configurations as well as by enhancing the convective/conductive heat transfer within the PCM. In this paper, we also discuss about the optimum system configurations and provide the general guidelines for designing these systems. Preliminary estimates of night time operations indicate it is possible to achieve over $10 \mathrm{~h}$ of operation with a relatively small quantity of Silicon.
\end{abstract}

Keywords: Solar energy; Thermal storage; Phase change material; Photovoltaics; Concentrating solar power; Solar thermophotovoltaics

\section{Introduction}

One of the main challenges in implementing renewable energy technologies for power generation, when compared to fossil fuel technologies, is the lack of continuous and reliable power supply. This reduces their load factor ${ }^{1}$ and therefore, the net generated energy using these technologies is limited. For this reason, a particularly interesting renewable alternative are the Concentrated Solar Power (CSP) technologies Barlev et al. (2011), which allow for thermal storage and consequently, the load factors can be made comparable to that of the conventional fossil fuel technologies. Different types of CSP technologies have been proposed so far (Barlev et al., 2011), and many of them are being installed on a large scale. As a reference, in the period of 2009-2010 the worldwide CSP capacity has increased from $430 \mathrm{MW}$ to $1300 \mathrm{MW}$ (Sunshot Vision Study, 2012) and at the beginning of 2011, a total capacity of about $20 \mathrm{GW}$ were under construction worldwide (Ardani and Margolis, 2011): $11 \mathrm{GW}$ in the US, $4.5 \mathrm{GW}$ in Spain, and $2.5 \mathrm{GW}$ in China. Besides, the International Energy Agency (IEA) estimates CSP will growth to several hundred GWs by 2050. Particularly, in the US, the Department 
of Energy has recently published that it is expected that $8 \%$ of the US electricity demand will be covered by CSP by 2050 (Sunshot Vision Study, 2012). In addition, several other countries that lie in the latitudes between $15^{\circ}$ and $35^{\circ}$, identified by the IEA as having best potential for solar power, such as India, China and Australia are expected to make investments in CSP to increase their portfolio of renewables.

In order to make this technology profitable and thereby increase the fraction of CSP in power generation, it is necessary to reduce the cost of produced electricity (Sunshot Vision Study, 2012). To accomplish this target, we need to: (1) increase the conversion efficiency and/or (2) reduce the system cost. For the item (1), the main drawback is that the operating temperature of conventional CSP systems, is fundamentally limited by the thermal stability of the heat transfer fluid (HTF) used for transferring the heat from the receiver to the working fluid (Olivares, 2012). As a result, most of the mature CSP technologies (Parabolic Trough collector and Linear Fresnel reflector (Barlev et al., 2011)) rarely surpass operation temperatures and efficiencies of $400{ }^{\circ} \mathrm{C}$ and $25 \%$, respectively. More recent technologies like Dish-Stirling and Solar Towers (Barlev et al., 2011) have the potential for higher temperatures and efficiencies, but at the expense of requiring a much more complex system configuration, which adds to the cost of the electricity production. This also relates to item (2), for which most of the current research is focusing on finding new materials for HTF and thermal energy storage (TES), as well as reducing the cost of dry cooling technologies and increasing the installation size to minimize both power block and operation/maintenance costs.

In this paper, we analyze a novel CSP solution that aims to simultaneously reduce the cost and increase the efficiency of currently available CSP systems, through the use of thermophotovoltaic (TPV) technology. The operating principle of a TPV system is simple (Bauer, 2011; Chubb, 2007; Coutts, 1999): an incandescent material (in this case, heated by concentrated sunlight) radiates towards a photovoltaic (PV) cell which directly produces electricity. In this arrangement, the spectral emissivity of the emitting surface can be engineered to match the PV cells spectral response, enabling an extremely high PV conversion efficiency (much higher than conventional solar PV cells (Davies and Luque, 1994; Harder and Würfel, 2003; Bell, 1979; Badescu, 2005; Edenburn, 1980). The key aspect of the design is the option of integrating a phase-change material (PCM), in which a solid is melted, capturing and storing a considerable amount of thermal energy as latent heat.

As explained elsewhere (Bauer, 2011; Chubb, 2007), TPV technology has a great potential to boost the heat-to-electricity conversion efficiency, even above $50 \%$. As a reference, the best reported experimental efficiency up to date was reported in 2004 and it is of $23.6 \%$ at $1039^{\circ} \mathrm{C}$ emitter temperature (Wernsman et al., 2004). However, the main short-term benefit of this technology lies in its great potential for cost reduction and in its higher reliability than other CSP solutions:
First, it neither requires any working fluid nor moving parts to convert heat into electricity, which minimizes the complexity of the system (power block cost) and potentially, also the maintenance cost. Second, the spectral tailoring of the radiation incident upon the PV cells drastically reduces the heat that must be dissipated from them, avoiding the use of complex and expensive wet cooling solutions. Another benefit is that it is a modular and scalable technology, allowing meeting the needs of each individual project site or alternatively being used off-grid. Finally, it is worth noting that this technology can take advantage of the recent advances in the fields of concentrating PV (CPV) cells and nanophotonic devices.

Storage integrated solar TPV (coined as SISTPV here for the first time) systems were first assessed at the US aerospace manufacturer McDonnell Douglas (later merged with Boeing) in the mid 1990s for both space and terrestrial applications (Stone et al., 1994a,b,c,d, 1995a,b, 1996a,b). Unfortunately, the project ended before any prototype including thermal storage was built. Other Solar-TPV prototypes were built by EDTEK Inc. (US) in early 00s (Horne, 2002) and at IES-UPM (Spain) Datas and Algora, 2012a; Datas, 2011 and Ioffe Institute (Russia) Andreev et al., 2007; Vlasov et al., 2006; Andreev et al., 2006 in the late 2000s-early 2010s, but none of them included a thermal storage unit.

A new SISTPV configuration was proposed by Chubb et al., (1995), which involved the use of a tapered design for the PCM material. This arrangement allows minimizing the temperature gradient between the absorber and the emitter, which is a key aspect to enhance the conversion efficiency and provide thermal storage simultaneously. More importantly, in Chubb et al. (1995) it was proposed the use of Silicon as PCM. Silicon is an excellent candidate for thermal storage because it is a non-corrosive and cheap material and importantly, because of its very high heat of fusion $(1800 \mathrm{~kJ} / \mathrm{kg})$ Shackelford and Alexander, 2001; Nakamura and Hibiya, 1992, which will allow much longer running times in the dark with a small amount of Si compared to a system that uses other PCMs like molten salts. That fact along with the simplicity of SISTPV compared to a mechanical energy converter is the major advantage of SISTPV.

Silicon has not been used so far as PCM for thermal storage because of its very high melting point $(1680 \mathrm{~K})$ that makes it difficult to integrate in "conventional" CSP systems. However, having such a high temperature, matches perfectly for its application in TPV technology where there is no fluid flow or physical contact between the hot body (emitter) and the PV cells. High emitter temperatures also help achieve higher output and efficiencies.

In this paper, we analyze a novel SISTPV system inspired by the one described in Chubb et al. (1995). This analysis will be carried out in the framework of the detailed balance theory (Shockley and Queisser, 1961; Araújo and Martí, 1994; Datas and Algora, 2010). A simplified 1D model for the heat transfer in the PCM has been used following reference (Chubb et al., 1995). In this model, natu- 
ral convection in the liquid Silicon is neglected. This assumption can be taken because the PCM container is kept vertical and heated from above, but any other arrangement, such as the inverted configuration (heated from below) would need a more sophisticated model to incorporate natural convection effects (Ismail and Melo, 1998; Huang et al., 2011; Lamberg and Siren, 2003). It is worth noting that natural convection within the PCM will result in improved heat transfer, so that the configuration analyzed in this paper represents a conservative estimate for the heat transfer within the PCM tank. Even further improvements could be achieved using more sophisticated heat transfer enhancement strategies, such as the inclusion of fins or heat pumps (Huang et al., 2011; Lamberg and Siren, 2003) within the PCM, but such advance modeling is beyond the scope of this paper.

This study will broaden the understanding of the influence of the system design variables on the performance of the SISTPV system and will provide general guidelines to design practical systems in the near future.

\section{System description}

The SISTPV system configuration analyzed in this paper is shown in Fig. 1. A sunlight concentrator based on the "fiber optic concentrator" concept (Antón et al., 2007; Arnaoutakis et al., 2013) (Fig. 1a) can be used for keeping the SISTPV unit vertically oriented during the full day. This, although not strictly necessary for these systems, avoids the convective motion of liquid Silicon owing to orientation changes and subsequently allows simplifying the thermal analysis within the PCM. The PCM is located in between the absorber and the emitter surfaces (Fig. 1b) and is contained in a tapered tank. As shown later, the tapered configuration allows the proper melting of the PCM (Chubb et al., 1995). The concentrated sunlight passes through a spectrally selective filter, located at the inlet of the absorber cavity. This filter transmits (rejects) the photons with energies higher (lower) than some specific threshold value $\varepsilon_{c a}$ (Datas and Algora, 2010), (Datas and Algora, 2012b), which is one of the design parameters that will be optimized in this paper. Similar strategies (spectrally selective absorbers or spectrally selective coatings) are commonly used in other CSP technologies to avoid excessive radiation losses from the absorber (Kennedy et al., 2002). The absorber cavity walls are assumed to be highly reflective and perfectly insulated, so that all the incoming energy is transferred to the absorber surface. Once the sunlight is absorbed and converted to heat at the absorber surface, this heat is conducted through the PCM (and in the process potentially melting the PCM) to the emitter, where it is radiated to the PV cells. Therefore, the PCM has a temperature profile with a higher temperature at the absorber side $\left(T_{a}\right)$ than at the emitter $\left(T_{e}\right)$. In this case, the PCM stores energy as latent heat of fusion if $T_{a}$ exceeds the melting temperature of the PCM $\left(T_{m}\right)$ and the storage energy density (total stored latent heat divided by the total PCM (a)
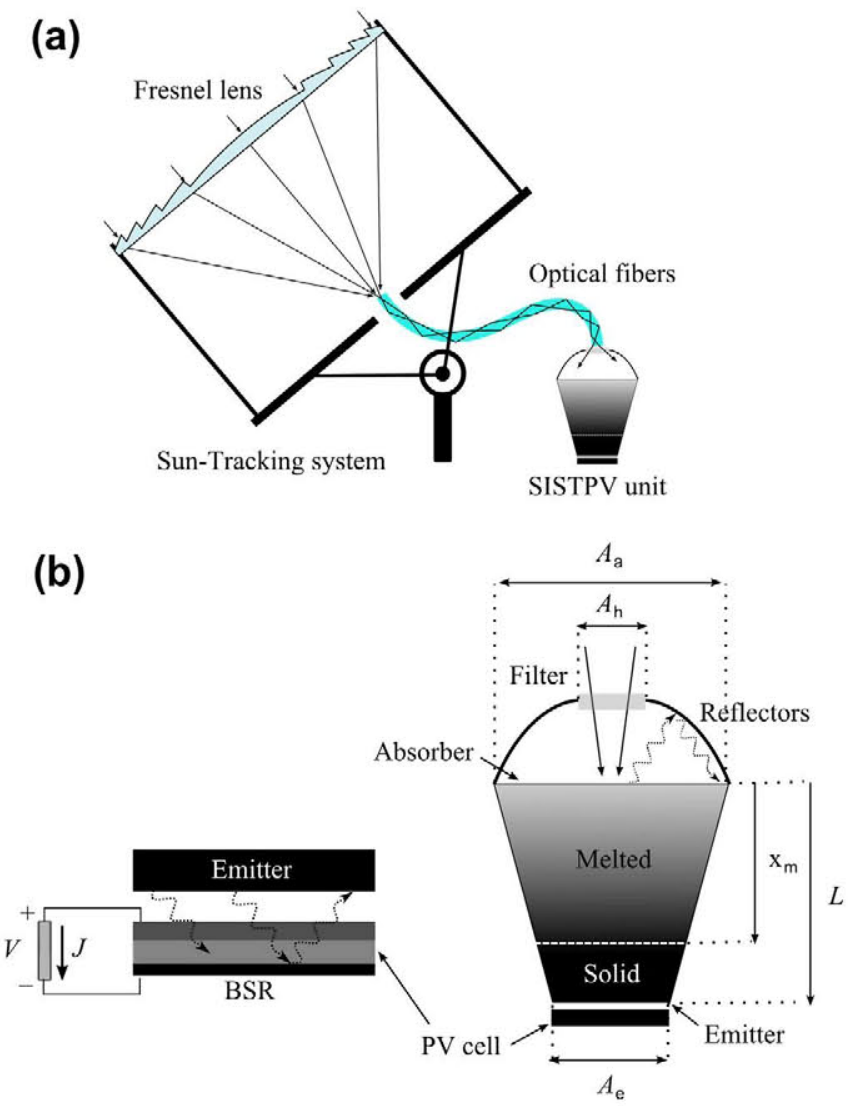

Fig. 1. (a) Overall view of the proposed SISTPV system using a fiber optic solar concentrator and (b) proposed configuration of the SISTPV unit. The concentrated sunlight passes through the spectrally selective inlet filter and is confined in the absorber cavity, heating the absorber surface and melting the storage PCM material (in our case Silicon). On the opposite side of the PCM, the emitter radiates towards the BSR PV cells, which convert that radiation into electricity.

weight) reaches its maximum when all the PCM is melted $\left(T_{e} \geqslant T_{m}\right.$ and $x_{m}=L$ in Fig. 1).

At the emitter/PV cells side, we assume a black body emitter and single junction PV cells with back-side reflectors (BSR) Wilt et al., 2003; Huang et al., 2004 as was done in earlier work (Datas and Algora, 2010, 2012b). The BSR reflects back to the emitter the photons that are not absorbed by the PV cells: mainly the photons with energies below the bandgap. Note that for this arrangement to be effective, it is required to have very low free carrier absorption within the bulk of the semiconductor PV cell substrate. Some materials like InP show very low free carrier absorption and consequently, they have been used as the substrate to manufacture TPV cells with BSR (Wilt et al., 2003). Another very promising approach to manufacture such cells is by developing thin film PV cells on highly reflective substrates (Wilt et al., 2003; Huang et al., 2004).

We want to note that great improvements could be achieved using narrow-band spectrally selective emitters (Chubb et al., 1995; Tobler and Durisch, 2008), multi-junction PV cells (Datas and Algora, 2012b; Wojtczuk et al., 1997) or near-field TPV configurations (Basu et al., 2009) as well as with the possible PCM heat transfer enhance- 
ments discussed previously (Huang et al., 2011; Lamberg and Siren, 2003). These aspects are currently under development in several research centers and companies and could have a great impact in the performance of future SISTPV systems. Nevertheless, we want to emphasize the main advantage of the selected configuration, regarding the ease of practical implementation due to the relatively simple and mature technologies that are employed.

\section{System modeling}

To obtain a solution for the absorber and emitter temperatures $\left(T_{a}\right.$ and $\left.T_{e}\right)$ in the SISTPV system of Fig. 2 we need to solve two equations simultaneously: (1) the radiative energy balance equation at the emitter and the absorber and (2) the steady-state heat conduction equation for the PCM. In order to obtain the globally optimized solution, we first make several simplifying assumptions that make the heat transfer problem tractable (summarized in Table 1). These will be explained in detail as they emerge over the course of the analysis and solution methodology.

We start our analysis with the energy balance at the absorber-inlet hole. If we assume that the convective heat losses are negligible (Table 1, assumption \#1), each element has an uniform temperature distribution (Table 1, assumption \#2), the apparent absorptivity/emissivity of the inlet is independent of the angle (Table 1, assumption \#3) and the filter is non absorptive (Table 1, assumption \#4), the net radiative power density (power per unit of area) at the absorber inlet can be written as (Datas and Algora, 2010, 2012b):

$$
\begin{aligned}
Q_{i n} / \pi= & \frac{C}{C_{\max }}\left[\alpha_{H} \dot{E}\left(\varepsilon_{c a}, \infty, T_{s u n}, 0\right)+\alpha_{L} \dot{E}\left(0, \varepsilon_{c a}, T_{s u n}, 0\right)\right] \\
& -\left[\alpha_{H} \dot{E}\left(\varepsilon_{c a}, \infty, T_{a}, 0\right)+\alpha_{L} \dot{E}\left(0, \varepsilon_{c a}, T_{a}, 0\right)\right]
\end{aligned}
$$

where $\dot{E}\left(\varepsilon_{1}, \varepsilon_{2}, T, \mu\right)$ is the energy flux emitted by a surface at temperature $T$ and with chemical potential $\mu$ in vacuum, in the spectral interval $\left(\varepsilon_{1}, \varepsilon_{2}\right)$, in the normal direction and per unit of solid angle:

$\dot{E}\left(\varepsilon_{1}, \varepsilon_{2}, T, \mu\right)=\frac{2}{h^{3} c^{2}} \int_{\varepsilon_{1}}^{\varepsilon_{2}} \frac{\varepsilon^{3}}{\exp [(\varepsilon-\mu) / k T]-1} d \varepsilon$

$\varepsilon_{c a}$ is the inlet filter cut-off energy, $\alpha_{H}$ is the apparent absoptivity/emissivity of the inlet hole (including the filter) for photons with $\varepsilon>\varepsilon_{c a}, \alpha_{L}$ is the apparent absorptivity/emissivity of the inlet hole (including the filter) for photons with $\varepsilon<\varepsilon_{c a}, C$ is the sunlight concentration factor and $C_{\max }$ is the maximum achievable concentration factor on the earth ( $C_{\max }=46,050$ suns for a point focus concentrator and assuming that the focus plane is surrounded by vacuum (Luque and Hegedus, 2003). Therefore, the first term of Eq. (1) (which is positive) represents the total heat absorbed by the inlet hole and the second term (which is negative) represents radiative losses from the inlet hole.

Note that the assumption \#4 (non absorptive filter or equivalently, filter temperature of $300 \mathrm{~K}$ ) allows neglecting the thermal radiation emanating from the filter. Also note that the apparent absorptivity of the inlet hole should be calculated by means of a rigorous radiative exchange analysis between the absorber cavity walls and the filter. However, if the cavity is properly designed, the optical confinement will result in a very high inlet hole absorptivity (approaching one) in a broad spectrum range (Chubb, 2007; Datas, 2011). Therefore, we can assume that the inlet-hole apparent absorptivity is mainly determined by the filter characteristics, which in this paper is assumed to be a one-step spectral transitivity function (Table 1, assumption \#5).

Assuming a lossless absorber cavity (Table 1, assumption \#6) and a lossless PCM tank (Table 1, assumption \#7), all the heat flows from the absorber inlet towards the emitter and the overall radiative energy balance in steady state is written as:

$A_{h} Q_{\text {in }}+A_{e} Q_{E}=0$

where $Q_{E}$ is the net radiative power density at the emitter surface. To obtain $Q_{E}$ it is required to analyze the radiative exchange in the TPV optical cavity, comprising of the emitter and any surface with which the emitter exchanges radiation (in a well designed system, mostly the PV cells). For this, we will employ the model presented in Datas and Algora $(2010,2012 \mathrm{~b})$ in which the PV cells are modeled according to the detailed balance theory and are assumed to work at the radiative limit (Table 1, assumption \#8). We reproduce the resultant energy balance equation here for completeness:

$$
\begin{aligned}
Q_{E} / \pi= & F_{e c} \dot{E}\left(\varepsilon_{G}, \infty, 300, q V\right)-\dot{E}\left(\varepsilon_{c e}, \infty, T_{e}, 0\right) \\
& +\frac{A_{e}}{A_{c}} \cdot \frac{\rho_{B S R} F_{e c}^{2}}{1-\rho_{B S R} F_{c c}^{(e)}} \dot{E}\left(\varepsilon_{c e}, \varepsilon_{G}, T_{e}, 0\right)
\end{aligned}
$$

In this equation, $F_{e c}$ is the emitter-to-cells view factor and $F_{c c}^{(e)}$ is the cell-to-cell view factor when the emitter is a shadowing obstacle. Both parameters can be used owing to assumption \#3 in Table 1). $q V$ is the chemical potential of the biased PV cells ( $V$ is the bias voltage), $\varepsilon_{G}$ is the bandgap energy of the PV cells, $\varepsilon_{c e}$ is the emitter cut-off energy (in this paper $\varepsilon_{c e}=0$, i.e. blackbody emitter: assumption \#9 in Table 1) and $\rho_{B S R}$ is the BSR reflectivity. Therefore, the first term of Eq. (4) represents the fraction of the luminescent radiation originating at the PV cells that is incident upon the emitter (and consequently is absorbed, since the emitter is assumed to be a black body). The second term represents the total power radiated by the emitter and the last term represents the portion of that emitted radiation that is turned back by the TPV cavity and finally reabsorbed at the emitter. Finally, introducing Eqs. (1) and (3) into Eq. (4), we obtain the overall radiative energy balance of the full SISTPV system, that relates the two unknown temperatures $T_{a}$ and $T_{e}$.

The general problem of the heat exchange within a PCM is very complex due to convective effects (Ismail and Melo, 1998; Huang et al., 2011; Lamberg and Siren, 2003). However, in a static, vertical PCM unit heated from above (Fig. 1), the problem is greatly simplified 
Table 1

List of main assumptions employed in this model.

\begin{tabular}{|c|c|}
\hline S. no. & Assumptions \\
\hline 1 & Negligible convective losses from any hot surface (absorber and emitter) \\
\hline 2 & Uniform temperature distribution at each component (emitter, absorber, PV cells, etc.) \\
\hline 3 & Diffuse emission from each surface (except from the BSR) \\
\hline 4 & Negligibly small inlet filter absorptivity across all wavelengths (filter temperature $\sim 300 \mathrm{~K}$ ) \\
\hline 5 & $\begin{array}{l}\text { Absorber cavity approximates a blackbody (apparent absorptivity of the hole approaches one) so that the inlet hole spectral characteristics are } \\
\text { mainly determined by the inlet filter. We approximate the inlet hole apparent spectral absorptivity as a one-step function with apparent } \\
\text { absorptivities levels } \alpha_{H} \text { and } \alpha_{L} \text { and a sharp cut-off at } \varepsilon_{c a}\end{array}$ \\
\hline 6 & Loss-less absorber cavity (thermally insulated) \\
\hline 7 & Loss-less PCM tank (thermally insulated side walls) \\
\hline 8 & $\begin{array}{l}\text { PV cells are single PN junctions with back side reflectors (BSR) operating in the radiative limit and at } 300 \mathrm{~K} \text {. Several assumptions derived from } \\
\text { this one are described in Datas and Algora }(2010,2012 \mathrm{~b})\end{array}$ \\
\hline 9 & Blackbody emitter \\
\hline 10 & $\begin{array}{l}\text { Quasi 1-D heat conduction in the phase change material }(T=T(x)) \text {. This allows an analytical solution to be obtained, simplifying the } \\
\text { optimization problem }\end{array}$ \\
\hline 11 & No convective motion of solid Silicon pieces within the liquid phase in the PCM tank \\
\hline
\end{tabular}

because the buoyancy forces do not create large convective motion of liquid Silicon within the container (Kreith, 2000). Therefore, the heat transfer is mostly by conduction. For the sake of simplicity, other convective effects such as the entrainment of solid Silicon pieces upwards in the melted part are neglected (Table 1, assumption \#11). Also, 2/3 dimensional effects, that may be important under some circumstances (Huang et al., 2007; Verma, 2008; Bailey, 2010; Naaktgeboren, 2007; Hsieh, 1995), are not considered in this paper and a quasi-1D approximation will be used (Table 1, assumption \#10). Under these assumptions, the steady state heat transfer in the PCM can be simply modeled by the quasi-1D Fourier law of thermal conduction, which in the absence of losses in the PCM container walls (Table 1, assumption \#7) can be written as:

$A_{h} Q_{i n}=-k_{l, s} A(x) \frac{\partial T}{\partial x}$

where $k_{l, s}$ represents either the liquid/solid phase thermal conductivity of the PCM material and $A(x)$ is the cross section area of the PCM container at a given location $x$. Using simple trigonometric relations we can obtain the function $A(x)$ for the case of a square cross-section PCM container:

$A(x)=A_{a}(1+T R-2 \sqrt{T R}) \cdot\left(\frac{x}{L}-\frac{1}{1-\sqrt{T R}}\right)^{2}$

where $T R=A_{e} / A_{a}$. Introducing $A(x)$ into Eq. (5) and integrating we get the final expression for the conductive heat transfer within the PCM:

$\frac{L}{A R \sqrt{T R}} Q_{i n}= \begin{cases}k_{s}\left(T_{m}-T_{e}\right)+k_{l}\left(T_{a}-T_{m}\right) & \text { if } T_{a}>T_{m}>T_{e} \\ k_{s}\left(T_{a}-T_{e}\right) & \text { if } T_{a}<T_{m} \\ k_{l}\left(T_{a}-T_{e}\right) & \text { if } T_{e}>T_{m}\end{cases}$

where $A R=A_{a} / A_{h}$. Note that to obtain this equation, the integration of Eq. (5) must be performed from the absorber $(x=0)$ to the emitter surface $(x=L)$ in either of the last two cases $\left(T_{\alpha}<T_{m}\right.$ or $\left.T_{e}>T_{m}\right)$ and from the absorber and emitter to the solid/liquid interface $\left(x=x_{m}\right)$ if $T_{a}>T_{m}>\mathrm{Te}$.

Combining Eqs. (1), (3), (4), and (7) we can obtain both the emitter and absorber temperatures $\left(T_{a}\right.$ and $\left.T_{e}\right)$. Then, the position of the solid/liquid interface can be expressed in terms of $T_{a}$ by integrating Eq. (5) from the absorber $(x=0)$ to the solid/liquid interface $\left(x-x_{m}\right)$.

$x_{m}=-\frac{k_{l}\left(T_{m}-T_{a}\right)}{(\pi L / A R) Q_{i n}-k_{l}\left(T_{m}-T_{a}\right)(1-\sqrt{T R})}$

The steady state melting ratio $(M R)$ of the PCM, defined as the percentage of the total PCM volume that is melted in the steady state, is a good merit function to evaluate the effective storage energy density of the system. This quantity can be expressed in terms of $x_{m}$ as follows:

$M R=\frac{x_{m}}{L}\left(\frac{2-\left(x_{m} / L\right)(1-T R)}{1+T R}\right)$

Note that $M R=1$ if $x_{m}=1$, which means that all the PCM is melted. And, $M R=0$ if $x_{m}=0$, which means that all the PCM is still solid and no storage is accomplished by latent heat of fusion.

Finally, to obtain the system efficiency we need to calculate the current-voltage characteristic of the PV cells within the system. For that, we make use again of the results presented in Datas and Algora (2010), in which the electrical current density of the PV cells is given as:

$$
\begin{aligned}
\frac{J}{q \pi}= & \frac{A_{e}}{A_{c}} F_{e c} \dot{N}\left(\varepsilon_{G}, \infty, T_{e}, 0\right) \\
& -\left(1-F_{c c}^{(e)}\right) \dot{N}\left(\varepsilon_{G}, \infty, 300, q V\right) \\
& -n_{\text {int }}^{2}\left(1-\rho_{B S R}\right) \dot{N}\left(\varepsilon_{G}, \infty, 300, q V\right)
\end{aligned}
$$

where $\dot{N}\left(\varepsilon_{1}, \varepsilon_{2}, T, \mu\right)$ has the same meaning than $\dot{E}\left(\varepsilon_{1}, \varepsilon_{2}, T, \mu\right)$ but for the photon flux instead of the energy flux:

$\dot{N}\left(\varepsilon_{1}, \varepsilon_{2}, T, \mu\right)=\frac{2}{h^{3} c^{2}} \int_{\varepsilon_{1}}^{\varepsilon_{2}} \frac{\varepsilon^{2}}{\exp [(\varepsilon-\mu) / k T]-1} d \varepsilon$ 
$n_{\text {int }}$ is the refraction index of the PV cell semiconductor, which in this study is assumed to be 3.5 , independent of the photon energy (Datas and Algora, 2012b) (Table 1, assumption \#8). Then, the electrical power density generated by the system is obtained by:

$P_{E L}=J_{M P} V_{M P}$

where $J_{M P}$ and $V_{M P}$ are the current density and the voltage at the maximum power point of the J-V curve. Finally, the full SISTPV system efficiency can be formulated as the product of three efficiencies: the absorber efficiency, the PCM efficiency and the TPV efficiency:

$$
\begin{aligned}
\eta_{\text {SISTPV }} & =\eta_{\text {abs }} \eta_{P C M} \eta_{\text {TPV }} \\
& =\left(\frac{Q_{\text {in }} / C}{Q_{\text {sun }} / C_{\text {max }}}\right) \cdot\left(\frac{A_{e} Q_{E}}{A_{h} Q_{\text {in }}}\right) \cdot\left(\frac{A_{c} P_{E L}}{A_{e} Q_{E}}\right)
\end{aligned}
$$

where $Q_{s u n}=\pi \dot{E}\left(0, \infty, T_{\text {sun }}, 0\right)$ is the solar irradiance at the sun's surface ( $\sigma$ is the Stefan-Boltzmann constant). Note that in this paper we have assumed that there is no heat loss from the PCM tank side walls, implying that $\eta_{P C M}=1$ (Eq. (3)). Furthermore, note that the concentrator efficiency is not included in this definition, so that $\eta_{\text {SISTPV }}$ represents the efficiency of the thermal storage and generator unit only. Both Eqs. (9) and (13) will be used as the merit functions to evaluate the performance of the SISTPV system.

\section{Solution methodology}

For a given system configuration (PV cell-band gap, sunlight concentration, PCM length, etc.) Eqs. (3) and (7) must be solved simultaneously to obtain the absorber and emitter temperatures $\left(T_{a}\right.$ and $\left.T_{e}\right)$. This is accomplished by employing the two-dimensional Newton method. Once both $T_{a}$ and $T_{e}$ are known we can calculate all the merit functions (for instance, the system efficiency and the melting ratio) to evaluate whether the adopted configuration is good or not. Therefore, the key challenge of this analysis is in using a proper strategy to explore the different system configurations.
To do this, we classify the parameters that define the system into four types: geometrical parameters, spectral control parameters, PV cells parameters and PCM parameters (Table 2). We identify some parameters whose optimum values can be easily deduced. For instance, it is obviously desirable that both the emitter-to-cells view factor and the BSR reflectivity approach one $\left(F_{e c} \rightarrow 1\right.$ and $\rho_{B S R} \rightarrow 1$ respectively) and that the apparent absorptivity/emissivity of the absorber inlet in the high (low) photon energy range tends to one (zero), i.e. $\alpha_{H} \rightarrow 1$ and $\alpha_{H} \rightarrow 0$. In this paper, we fix the values of those parameters to an optimistic (but realistic) value (Table 2). Other parameters that will be fixed in this paper are the material properties of the PCM (solid/liquid phase conductivities and melting temperature), since we are analyzing only Silicon as the PCM (Table 2). Furthermore, we will assume that the cells do not see each other (they only see the emitter) which allows to make $F_{c c}^{e}=0$ and $A_{e} / A_{c}=1 / F_{e c}$ and eliminate two more variables.

As a consequence of these reasonable assumptions, the degrees of freedom of the SISTPV system are reduced to seven parameters, four of them are geometrical configuration parameters $(C, L, T R, A R)$ and the other three are the PV cells band-gap energy $\left(\varepsilon_{G}\right)$, the inlet filter cut-off energy $\left(\varepsilon_{c a}\right)$ and the PV cells bias voltage $(V)$.

In this paper we will focus on the influence of the four aforementioned geometrical parameters on the system performance. To accomplish that, we will explore different configurations for optimized (i.e. provides maximum system efficiency) bandgap energy, inlet filter cut-off energy and PV cells voltage (i.e. corresponding to the maximum power point of the IV curve, $V=V_{M P}$ ). To find the optimum value of these three parameters we will use the multidimensional direct search Nelder-Mead algorithm (Lagarias et al., Dec. 1998).

\section{Discussion}

The SISTPV system analyzed in this work must provide the highest conversion efficiency and the maximum storage

Table 2

\begin{tabular}{|c|c|c|c|}
\hline Type of parameters & Fixed & Explored & Optimized \\
\hline Geometrical & $\begin{array}{l}F_{e c}=0.95 \\
F_{c c}^{(e)}=0 \rightarrow A_{e} / A_{c}=1 / F_{e c}\end{array}$ & $\begin{array}{l}C \\
L \\
T R=A_{e} / A_{a} \\
A R=A_{a} / A_{h}\end{array}$ & - \\
\hline Spectral control & $\begin{array}{l}\alpha_{H}=0.95 \\
\alpha_{L}=0.05 \\
\rho_{B S R}=0.9 \\
\varepsilon_{c e}=0 \mathrm{eV}\end{array}$ & - & $\varepsilon_{c a}$ \\
\hline PV cell & & - & $\begin{array}{l}\varepsilon_{G} \\
V\end{array}$ \\
\hline PCM (Silicon) & $\begin{array}{l}T_{m}=1680 \mathrm{~K} \\
k_{s}=20 \mathrm{~W} / \mathrm{m}-\mathrm{K} \\
k_{l}=60 \mathrm{~W} / \mathrm{m}-\mathrm{K}\end{array}$ & - & - \\
\hline
\end{tabular}

Summary of the parameters defining the SISTPV system analyzed in this paper. 
energy density simultaneously. Therefore, we aim to explore the influence of the different system parameters (solar concentration factor, PCM length, PCM tapered ratio, the absorber-to-inlet hole area ratio, inlet filter cutoff energy and PV cells bandgap energy) with these objectives as the target.

\subsection{Trade off between storage and efficiency}

In this section we will illustrate the existing trade-off between conversion efficiency and storage ability of a SISTPV system. Fig. 2 shows the conversion efficiency of the SISTPV system as a function of the PCM length for several PCM tapered ratios $(T R)$. In this particular case, $A R$ parameter is optimized together with $\varepsilon_{G}$ and $V$ and we have set $C=C_{\max }$ and $\varepsilon_{c a}=0$ (without filter at the inlet hole). We see that the maximum efficiency is achieved when $L \rightarrow 0$, which implies no thermal storage. This means that any attempt to perform thermal storage will imply a decrease in system efficiency. This fact is related to the temperature difference that appears between the emitter and absorber due to the finite thermal conductivity of the PCM. As can be seen from Fig. 2, the best way to minimize this impact is through the parameter $T R$. In the limiting case of $T R \rightarrow 0$ the temperature gradient tends to zero $(\Delta T \rightarrow 0)$ regardless of the PCM length $L$ and the SISTPV system efficiency is maximized. This finding will be dealt with in more detail in the remaining sections.

\subsection{Analysis of the sunlight receptor configuration}

In this section, we analyze the effect of the parameters controlling the input power received by the system. These are: the concentration ratio $(C)$, the $A R$ parameter and the spectrally selective filter at the absorber inlet. Figs. 3-6 explore the influence of $C$ and $A R$ on parameters such as melting ratio $(M R)$, optimum bandgap energy, optimum cut-off

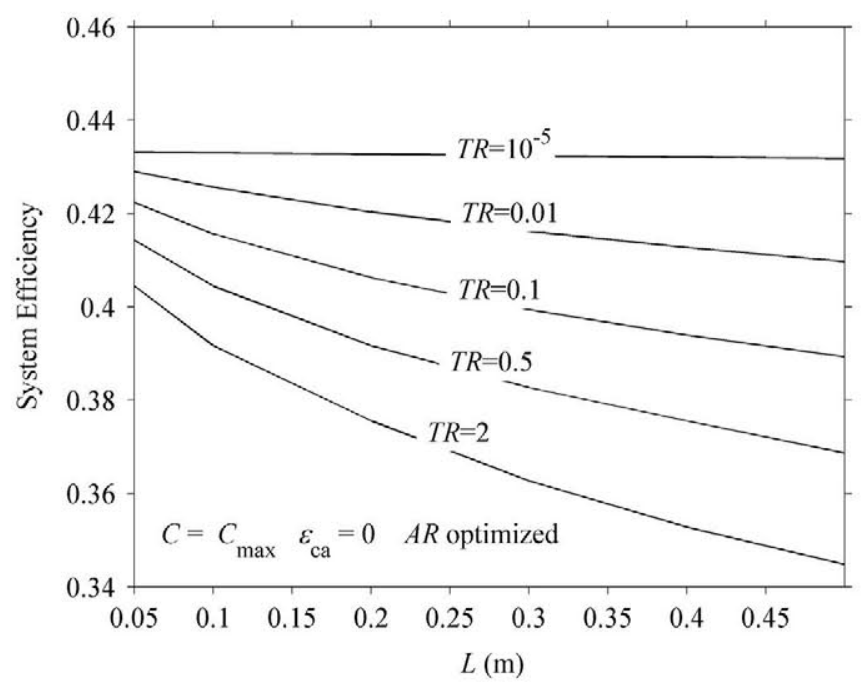

Fig. 2. SISTPV system efficiency as a function of the PCM length $(L)$ for $C=C_{\max }, \quad \varepsilon_{c a}=0$ (equivalent to a grey body absorber with 0.95 absorbtivity) and with optimized $A R$ parameter. energy of the inlet filter and temperature difference $(\Delta T)$ for a fixed $L=10 \mathrm{~cm}$ and $T R=0.3$. Figs. $3 \mathrm{a}$ and $\mathrm{b}$ show the efficiency and the $M R$ of a SISTPV system as a function of $C$ and $A R$. Fig. 3a shows the case of optimized inlet filter cut-off energy and Fig. $3 \mathrm{~b}$ shows the case of a grey body absorber $\left(\varepsilon_{c a}=0, \alpha_{H}=0.95\right)$, for which a transparent window is placed instead of the filter at the absorber inlet.

Figs. $3 \mathrm{a}$ and $3 \mathrm{~b}$ demonstrate the key benefit of using a spectrally selective filter at the inlet hole: it allows lowering the range of solar concentration for which (1) the PCM can be fully melted $(M R=1)$ and (2) the conversion efficiency is high. A spectrally selective filter reduces the emission losses from the absorber inlet hole, keeping the PCM hot even for lower solar concentrations. On the contrary, if no filter were used (grey/blackbody absorber, Fig. 3b), the melting of the PCM would be only possible for very high concentrations and the conversion efficiency would be drastically decreased in a broad range of concentration factors (a more detailed discussion on the relation between concentration factor and spectrally selective absorbers can be found in Datas and Algora (2012b)). Therefore, in subsequent analyses in this paper, we will only consider the case of a spectrally optimized, selective filter located at the inlet hole (such as in Fig. 3a).

From Fig. 3a we see that for a given concentration level, there exists an optimum $A R$ that maximizes the efficiency. For values of $A R$ above that optimum, the TPV efficiency decreases (see Fig. 4) and if $A R$ is below that optimum, the absorber efficiency decreases (see Fig. 5). Therefore, the optimum $A R$ represents the fulfillment of a trade-off between TPV conversion efficiency and absorber radiative losses.

Figs. 4 and 5 show (for the case of optimized inlet filter cut-off energy) the TPV and absorber efficiencies with superimposed optimum bandgap and filter cut-off energies,

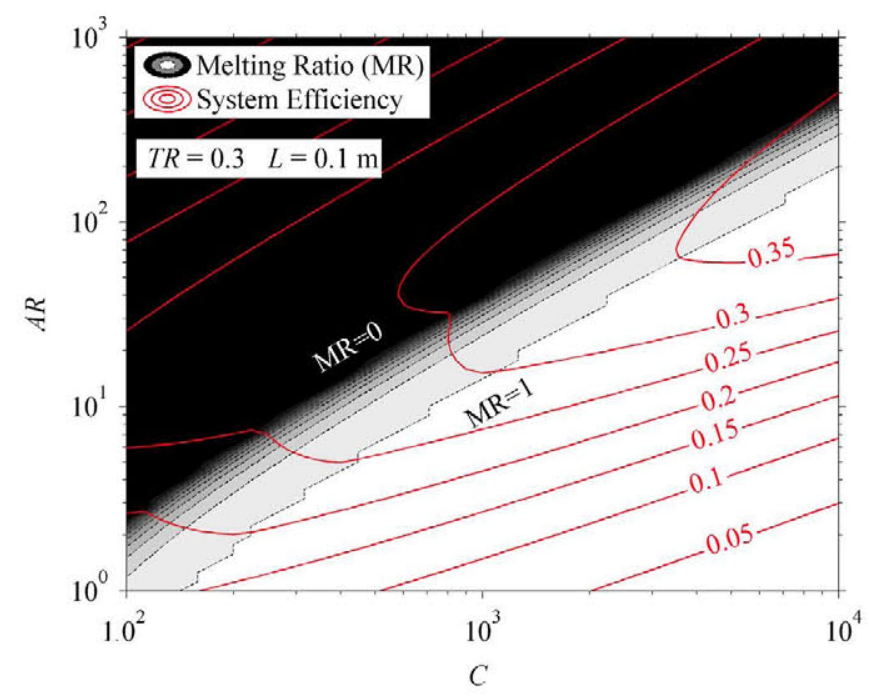

Fig. 3a. Contour-plot of the Melting Ratio $(M R)$ with superimposed isosystem efficiency curves (solid red lines), as a function of the concentration factor $(C)$ and $A R$ parameters. In this simulation $T R=0.3, L=0.1$ and the PV cell bandgap $\left(\varepsilon_{G}\right)$ and inlet filter cut-off $\left(\varepsilon_{c a}\right)$ energies are optimized. (For interpretation of the references to colour in this figure legend, the reader is referred to the web version of this article.) 


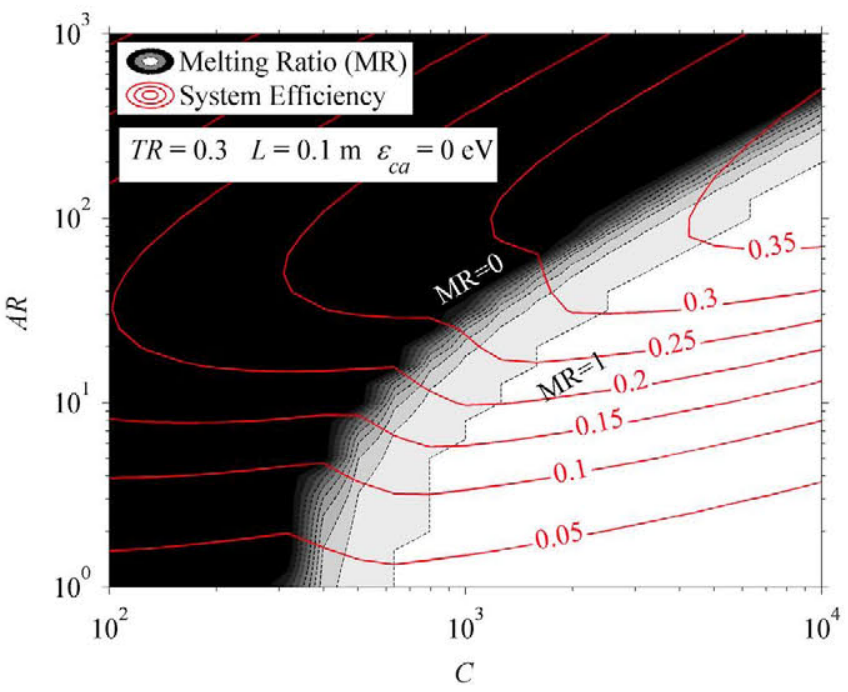

Fig. 3b. Contour-plot of the Melting Ratio $(M R)$ with superimposed isosystem efficiency curves (solid red lines), as a function of the concentration factor $(C)$ and $A R$ parameters. In this simulation $T R=0.3, L=0.1$ and the inlet filter cut-off $\left(\varepsilon_{c a}\right)$ energy is zero (grey body absorber, with $\alpha_{H}=0.95$ ). The PV cell bandgap $\left(\varepsilon_{G}\right)$ is optimized. (For interpretation of the references to colour in this figure legend, the reader is referred to the web version of this article.)

respectively. Fig. 6 shows the emitter temperature and the temperature difference between the absorber and the emitter $\left(\Delta T=T_{a}-T_{e}\right)$. From Figs. 4 and 5 we observe a clear correlation between the PV cell bandgap and the TPV efficiency and between the inlet filter cut-off energy and the absorber efficiency, respectively:

(1) The TPV efficiency (Fig. 4) is strongly related to three aspects: (a) the thermalization losses, (b) the radiative recombination at the $\mathrm{PV}$ cells and (c) the spectral

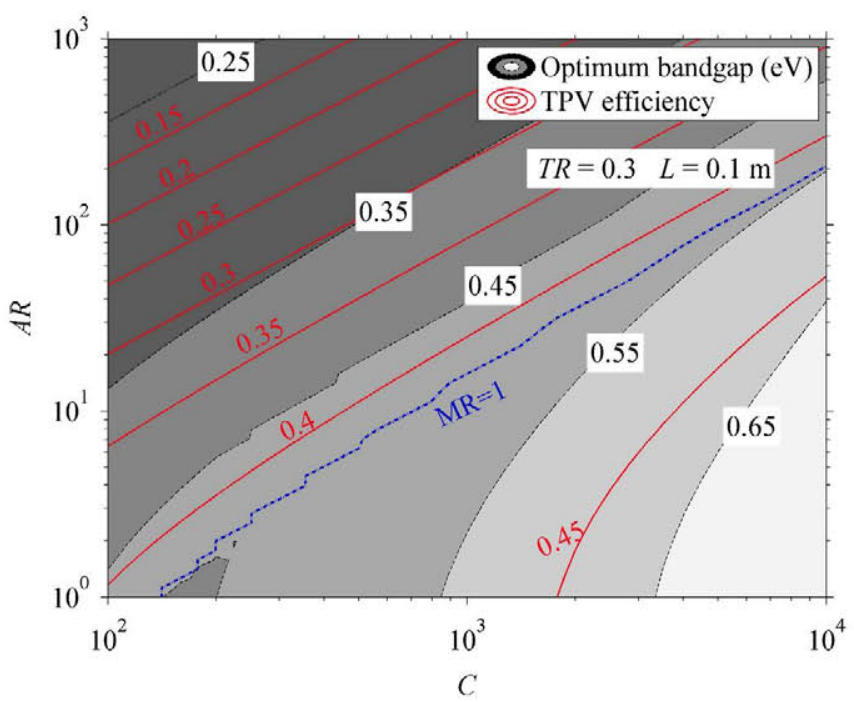

Fig. 4. Contour-plot of the optimum bandgap energy $\left(\varepsilon_{G}\right)$ with superimposed iso-TPV efficiency curves (solid red lines), as a function of the concentration factor $(C)$ and $A R$ parameters. In this simulation $T R=0.3$, $L=0.1$ and the PV cell bandgap $\left(\varepsilon_{G}\right)$ and inlet filter cut-off $\left(\varepsilon_{c a}\right)$ energies are optimized. (For interpretation of the references to colour in this figure legend, the reader is referred to the web version of this article.)

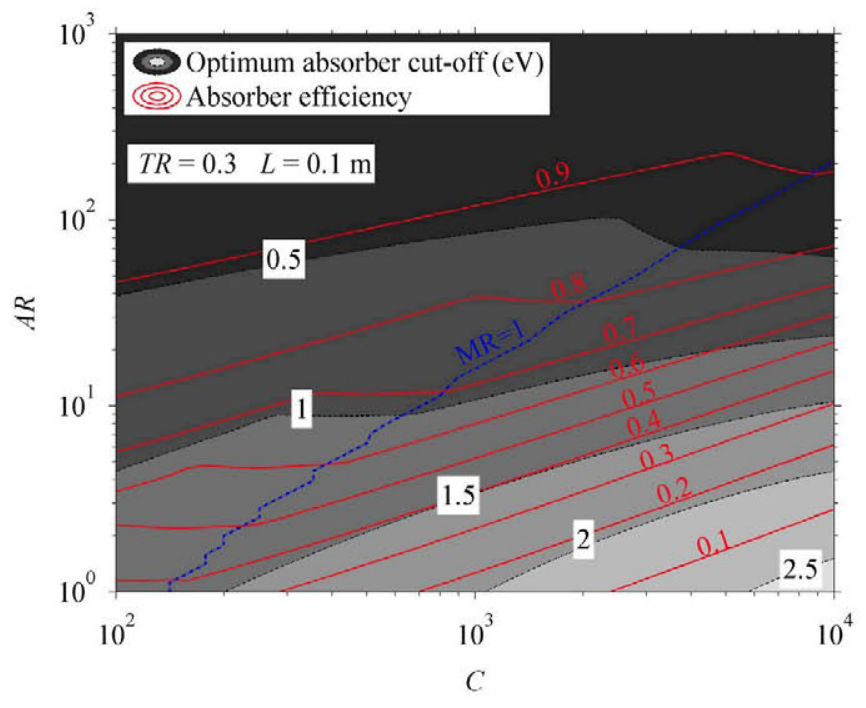

Fig. 5. Contour-plot of the optimum absorber cut-off energy $\left(\varepsilon_{c a}\right)$ with superimposed iso-absorber efficiency curves (solid red lines), as a function of the concentration factor $(C)$ and $A R$ parameters. In this simulation $T R=0.3, L=0.1$ and the PV cell bandgap $\left(\varepsilon_{G}\right)$ and inlet filter cut-off $\left(\varepsilon_{c a}\right)$ energies are optimized. (For interpretation of the references to colour in this figure legend, the reader is referred to the web version of this article.)

matching between the emitted radiation and the PV cell spectral response. The effects (a) and (b), both decrease for high bandgap energies and hence TPV efficiency tends to increase with the bandgap energy. On the contrary, due to the item (c) the optimum bandgap decreases with the emitter temperature. As a consequence, high bandgap energies are required

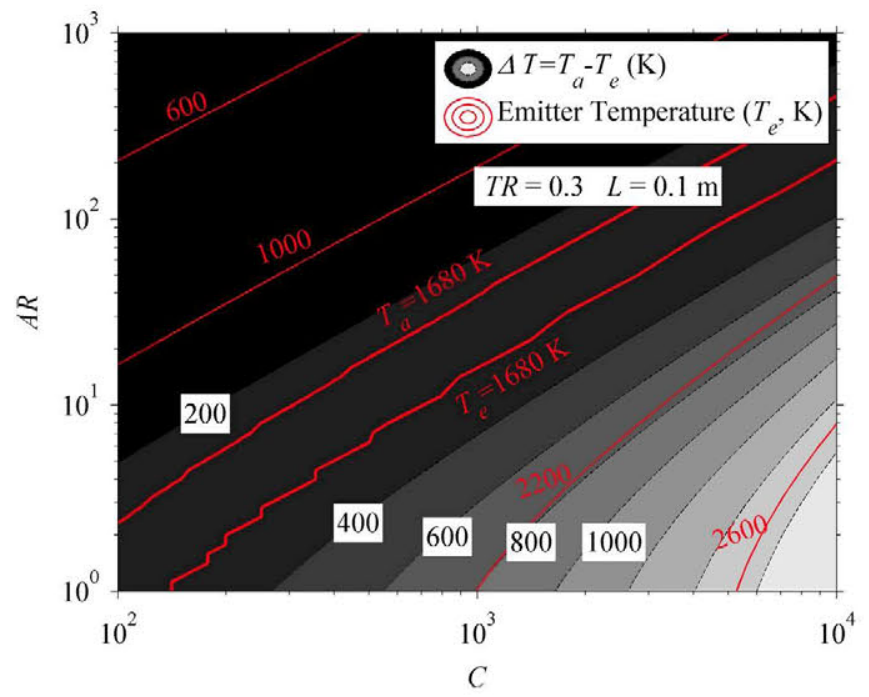

Fig. 6. Contour-plot of the temperature difference between the emitter and the absorber $\left(\Delta T=T_{a}-T_{e}\right)$ with superimposed iso-emitter temperature curves (solid red lines), as a function of the concentration factor $(C)$ and $A R$ parameters. The cases of $T_{e}$ and $T_{a}$ equaling $T_{m}=1680 \mathrm{~K}$ are specifically shown to identify the region $0<M R<1$. In this simulation $T R=0.3, L=0.1$ and the PV cell bandgap $\left(\varepsilon_{G}\right)$ and inlet filter cut-off $\left(\varepsilon_{c a}\right)$ energies are optimized. (For interpretation of the references to colour in this figure legend, the reader is referred to the web version of this article.) 
for low $A R$ in order to enhance the TPV conversion efficiency when the emitter temperature is high, but lower bandgaps are required for high $A R$, where the emitter temperature is low.

(2) The absorber efficiency (Fig. 5) is related to the amount of absorber radiative losses (relative to the total power transferred to the PV cells) which depends simultaneously on the emitter-to-inlet hole area ratio $\left(A_{e} / A_{h}\right)$ and the temperature gradient in the PCM $(\Delta T)$ (Fig. 6). If either $A_{e} / A_{h}$ is too low or $\Delta T$ is too high, the absorber efficiency will be poor. The use of a spectrally selective filter at the inlet hole minimizes the absorber emission losses and thereby mitigates the loss in absorber efficiency when $\Delta T$ is too high or $A_{e} / A_{h}$ is too low. This is the reason that we see the filter cut-off energy is particularly high for low $A R$ (low $A_{e} / A_{h}$ for a fixed $T R$ ) and high $\mathrm{C}$ (high $\Delta T$ due to the very high heat flux through the PCM) in Fig. 5.

In addition to high efficiency, in a SISTPV system, we should aim for maximum thermal storage energy density, i.e. $M R$ must approach one. We see from Figs. $3 \mathrm{a}$ and 6 that in order to have the highest efficiency along with having all the PCM melted $(M R=1)$, the emitter temperature should equal the PCM melting temperature $\left(T_{m}\right)$. Higher efficiencies would be possible for $T_{e}<T_{m}$ but at the expense of a poor melting ratio and storage energy density (see for example along $C=1000, A R$ between 10 and 30 in Figs. $3 \mathrm{a}$ and 6).

Emitter temperatures slightly lower than $T_{m}$ provide higher efficiencies because both the absorber temperature and the temperature gradient between the emitter and the absorber $(\Delta T)$ are lower, (Fig. 6) which in turn helps reduce the heat loss from the absorber side and hence improves efficiency. Therefore, the best design for any given concentration would be when the emitter temperature is equal to the PCM's melting temperature, with the choice of geometric parameters set to minimize the absorber losses.

Along the $M R=1$ line (suggested above as the optimum design configuration), we see that the TPV efficiency (Fig. 4) is slightly above $40 \%$ almost independent of the solar concentration (owing to the constant emitter temperature along that line) and the absorber efficiency (Fig. 5) is in the range of $40-90 \%$ depending on the concentration. Besides, we see that the optimum inlet filter cut-off energy (Fig. 5) is quite high for that line, especially if the concentration level is low. For instance, if we operate the system along this line and with $C=2000$, the optimum filter cut-off energy is $0.71 \mathrm{eV}$ but if $C=200$, the optimum is $1.3 \mathrm{eV}$. This behavior is explained by the fact that emitter temperature must be constant (equal to the melting temperature) along the $M R=1$ line. Then, since $T R$ and $L$ are fixed in this configuration, the decrease in the concentration level must be compensated by an increase in the filter cut-off energy to keep the emitter temperature constant.
Therefore, we conclude from this analysis that in order to maximize the efficiency and ensure the highest storage energy density, we should operate the system at the highest possible concentration and then tune the $A R$ parameter so that the emitter temperature approaches the melting temperature of the Silicon PCM $(1680 \mathrm{~K})$. Therefore, the critical parameters to be optimized are the inlet filter cut-off energy and the bandgap of the cells. The optimum PV cell bandgap has been found to be independent of concentration (about $0.5 \mathrm{eV}$ for Silicon PCM and $\rho_{B S R}=0.9$ ) while the optimum inlet filter cut-off decreases with concentration. However, this analysis holds true for the case of fixed $T R$ and $L(T R=0.3$ and $L=0.1)$. The following section will analyze the influence of these other two parameters to further optimize the system design.

\subsection{Analysis of the PCM container configuration}

Fig. 7a shows the influence of $A R$ and $T R$ on the efficiency and the $M R$ of a SISTPV system with fixed $L=10 \mathrm{~cm}$ and $C=1000$ suns. We have chosen this concentration because it is a notably high value and achievable with the current technologies (Barlev et al., 2011; Luque and Hegedus, 2003). Fig. $7 \mathrm{~b}$ shows the corresponding emitter temperature and the temperature difference between the absorber and the emitter $\left(\Delta T=T_{a}-T_{e}\right)$.

We see that in order to obtain the maximum efficiency along with $M R=1$ the emitter temperature should equal the PCM melting temperature for all values of $A R$. However, as can be seen from the figure, the optimum emitter temperature (for maximum efficiency) is still slightly lower than the PCM melting temperature, even for very low $A R$. Importantly, we see that the simultaneous attainment of high efficiency and melting ratio is more readily achievable

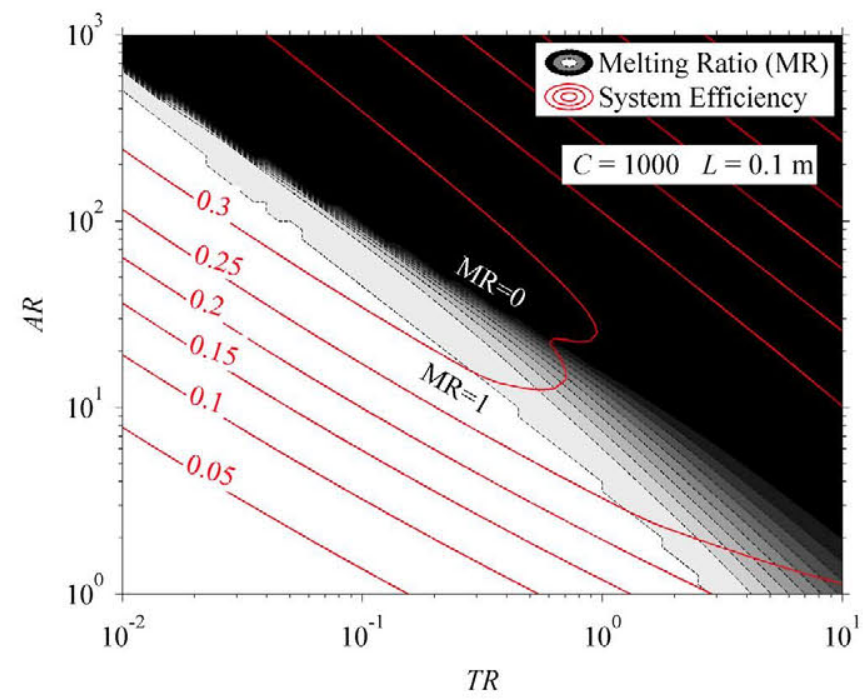

Fig. 7a. Contour-plot of the Melting Ratio $(M R)$ with superimposed isosystem efficiency curves (solid red lines), as a function of the $T R$ and $A R$ parameters. In this simulation $C=1000, L=0.1 \mathrm{~m}$ and the PV cell bandgap $\left(\varepsilon_{G}\right)$ and inlet filter cut-off $\left(\varepsilon_{c a}\right)$ energies are optimized. (For interpretation of the references to colour in this figure legend, the reader is referred to the web version of this article.) 


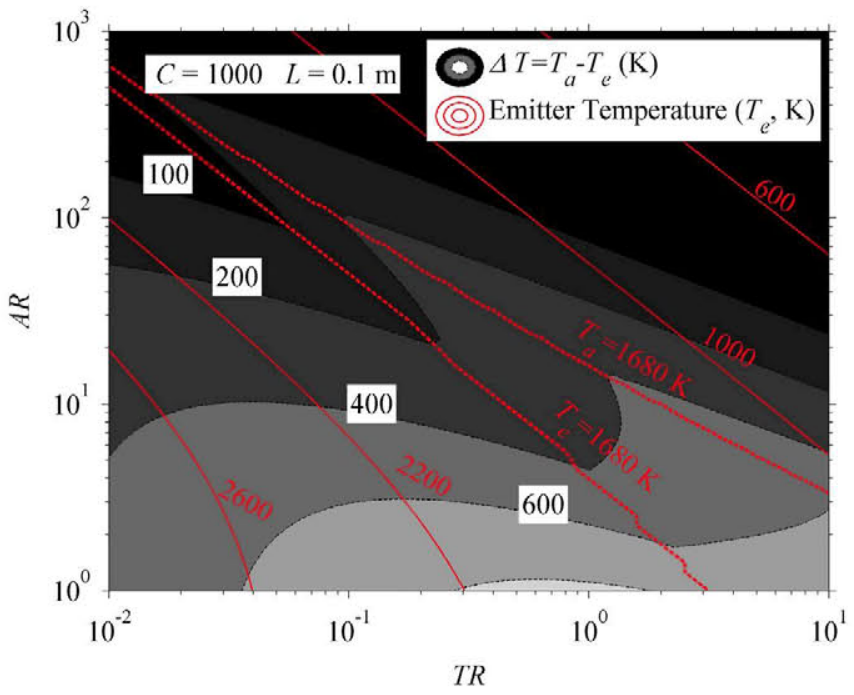

Fig. 7b. Contour-plot of the temperature difference between the emitter and the absorber $\left(\Delta T=T_{a}-T_{e}\right)$ with superimposed iso-emitter temperature curves (solid red lines), as a function of the $T R$ and $A R$ parameters. The cases of $T_{e}$ and $T_{a}$ equaling $T_{m}=1680 \mathrm{~K}$ are specifically shown to identify the region $0<M R<1$. In this simulation $C=1000, L=0.1 \mathrm{~m}$ and the PV cell bandgap $\left(\varepsilon_{G}\right)$ and inlet filter cut-off $\left(\varepsilon_{c a}\right)$ energies are optimized. (For interpretation of the references to colour in this figure legend, the reader is referred to the web version of this article.)

for low $T R$ and high $A R$. Indeed, if $T R$ is too high (especially if it is higher than one) achieving high efficiency and high melting ratio simultaneously, is particularly difficult. This is because the achievable emitter temperature is lower than the melting temperature of the PCM, owing to the large $A_{e} / A_{h}$ and $\Delta T$ (seen in Fig. 7b).

Figs. 8-10 explore the effect of the PCM length $(L)$ and taper ratio $(T R)$ on the systems efficiency and melting ratio

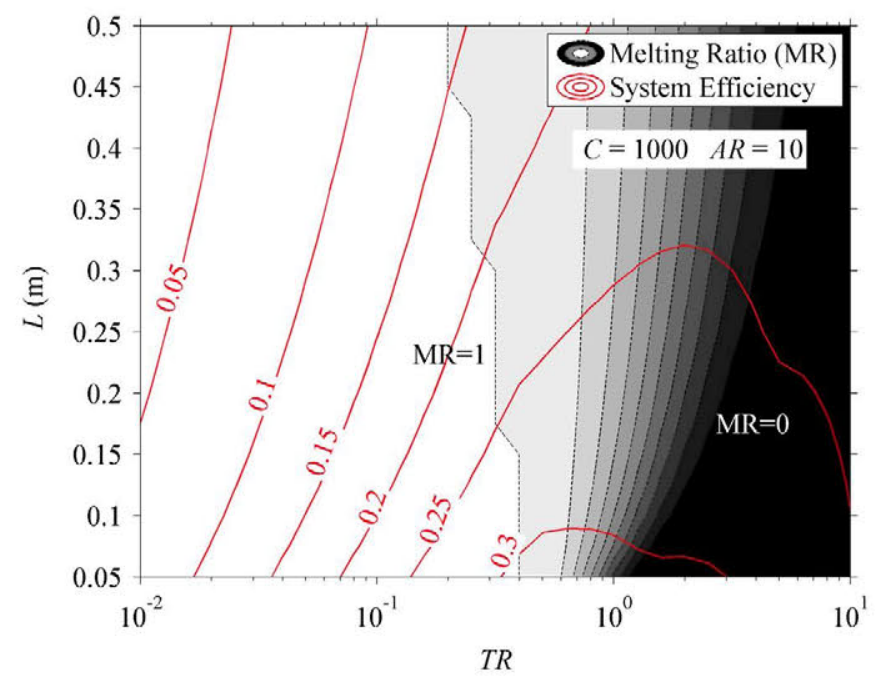

Fig. 8. Contour-plot of the Melting Ratio $(M R)$ with superimposed isosystem efficiency curves (solid red lines), as a function of the $T R$ and $L$ parameters. In this simulation $C=1000, A R=10$ and the PV cell bandgap $\left(\varepsilon_{G}\right)$ and inlet filter cut-off $\left(\varepsilon_{c a}\right)$ energies are optimized. (For interpretation of the references to colour in this figure legend, the reader is referred to the web version of this article.)

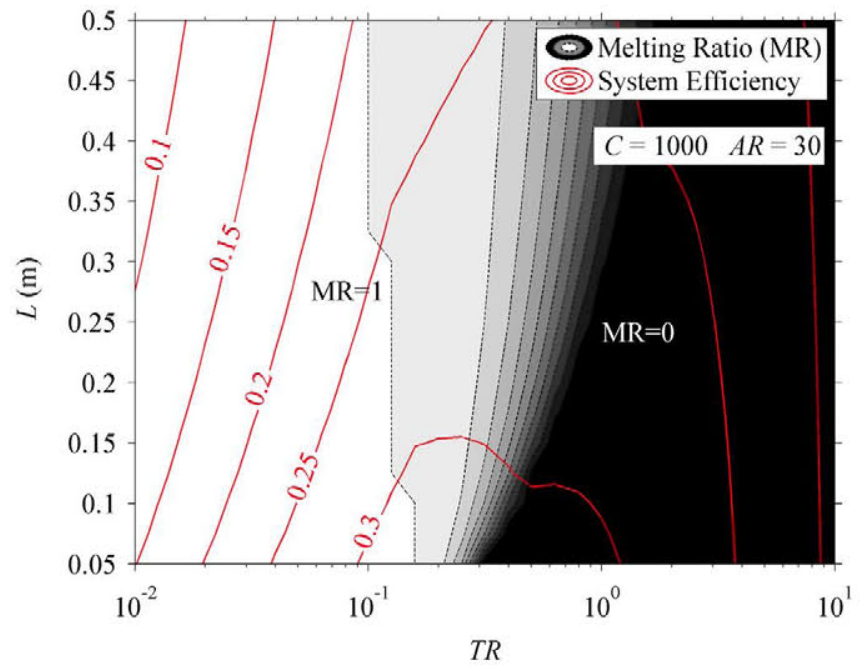

Fig. 9. Contour-plot of the Melting Ratio $(M R)$ with superimposed isosystem efficiency curves (solid red lines), as a function of the $T R$ and $L$ parameters. In this simulation $C=1000, A R=30$ and the PV cell bandgap $\left(\varepsilon_{G}\right)$ and inlet filter cut-off $\left(\varepsilon_{c a}\right)$ energies are optimized. (For interpretation of the references to colour in this figure legend, the reader is referred to the web version of this article.)

for three different values of $A R(10,30$ and 100 , respectively) and for $C=1000$.

From these figures we see that there exists an optimum value of $T R$ (for maximum efficiency) depending on the value of $A R$, being the optimum $T R$ lower for higher $A R$. For a given $A R$, if $T R$ is too low the energy transferred to the PV cells is very small and consequently, a lot of energy is lost as heat loss (via re-radiation) from the absorber causing low absorber efficiency. Conversely, if $T R$ is too high, the emitter temperature is very low and the TPV conversion efficiency is decreased. However, in both

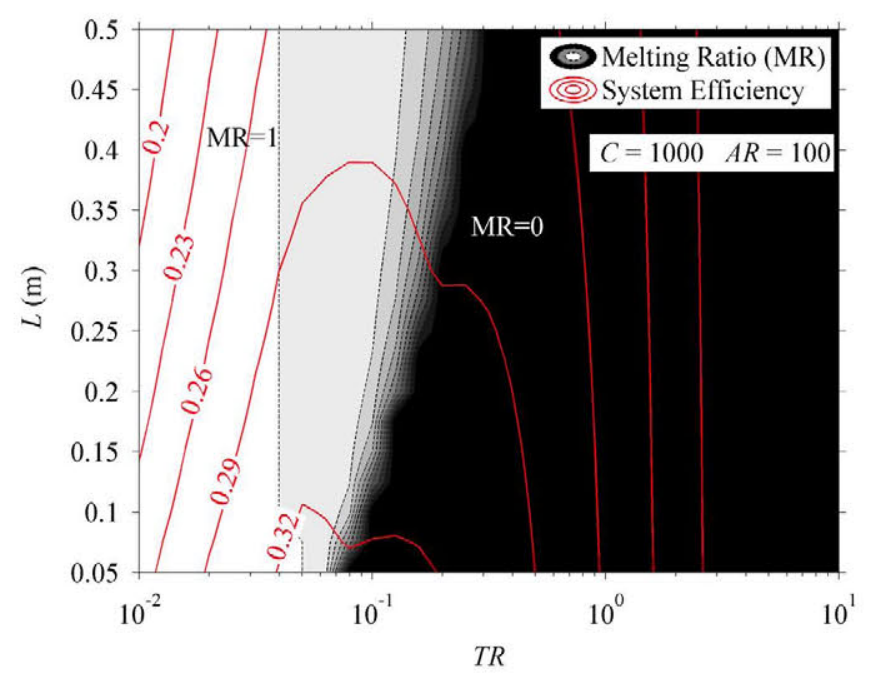

Fig. 10. Contour-plot of the melting ratio $(M R)$ with superimposed isosystem efficiency curves (solid red lines), as a function of the $T R$ and $L$ parameters. In this simulation $C=1000, A R=100$ and the PV cell bandgap $\left(\varepsilon_{G}\right)$ and inlet filter cut-off $\left(\varepsilon_{c a}\right)$ energies are optimized. (For interpretation of the references to color in this figure legend, the reader is referred to the web version of this article.) 
Table 3

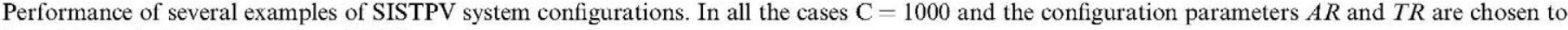
have $T_{\mathrm{e}}$ relatively close to $T_{\mathrm{m}}=1680 \mathrm{~K}$.

\begin{tabular}{|c|c|c|c|c|c|c|c|c|c|c|c|c|}
\hline \multicolumn{3}{|c|}{ Geometrical configuration } & \multicolumn{2}{|c|}{ Optimized parameters } & \multicolumn{6}{|c|}{ Output characteristics } & \multirow[t]{2}{*}{$M_{P C M} / A_{h}\left(\mathrm{~kg} / \mathrm{cm}^{2}\right)$} & \multirow[t]{2}{*}{$\overline{t_{\text {sol }}^{(L L)}(\mathrm{h})}$} \\
\hline$L(\mathrm{~m})$ & $A R$ & $T R$ & $\varepsilon_{c a}(\mathrm{eV})$ & $\varepsilon_{G}(\mathrm{eV})$ & $T_{\mathrm{a}}(\mathrm{K})$ & $T_{\mathrm{e}}(\mathrm{K})$ & $P_{E L}\left(\mathrm{~W} / \mathrm{cm}^{2}\right)$ & $\eta_{T P V}$ & $\eta_{a b s}$ & $\eta_{\text {SISTPV }}$ & & \\
\hline 0.1 & 10 & 0.3 & 1.03 & 0.510 & 2103 & 1788 & 14.5 & 42.2 & 64.9 & 27.4 & 0.14 & 0.7 \\
\hline 0.3 & 10 & 0.2 & 1.44 & 0.499 & 2546 & 1778 & 14.4 & 42.0 & 43.0 & 18.1 & 0.38 & 2.9 \\
\hline 0.5 & 10 & 0.2 & 1.61 & 0.481 & 2704 & 1686 & 11.3 & 41.3 & 34.2 & 14.1 & 0.64 & 6.2 \\
\hline 0.1 & 30 & 0.1 & 0.95 & 0.520 & 2008 & 1815 & 15.5 & 42.4 & 68.8 & 29.2 & 0.33 & 1.6 \\
\hline 0.3 & 30 & 0.1 & 1.14 & 0.498 & 2238 & 1744 & 13.1 & 41.8 & 58.7 & 24.6 & 0.99 & 5.5 \\
\hline 0.5 & 30 & 0.1 & 1.29 & 0.484 & 2398 & 1685 & 11.2 & 41.3 & 50.9 & 21.0 & 1.65 & 10.7 \\
\hline 0.1 & 100 & 0.03 & 0.90 & 0.526 & 1942 & 1833 & 16.2 & 42.6 & 71.4 & 30.4 & 0.93 & 4.3 \\
\hline 0.3 & 100 & 0.03 & 1.02 & 0.512 & 2092 & 1791 & 14.7 & 42.2 & 65.3 & 27.6 & 2.80 & 14.1 \\
\hline 0.5 & 100 & 0.03 & 1.12 & 0.500 & 2213 & 1753 & 13.4 & 41.9 & 59.9 & 25.1 & 4.67 & 25.6 \\
\hline
\end{tabular}

cases, a low $T R$ is required for the proper melting of the $\mathrm{PCM}$, in agreement with our previous discussion.

A key aspect that is apparent from these plots is that the impact of the PCM length on the system efficiency is reduced for high $A R$ values (Fig. 10). Therefore, it is possible to design a SISTPV system with a large $L$ (high energy storage ability) and high efficiency just increasing $A R$ and reducing $T R$. However, it is worth noting that large $L$ combined with high $A R$ and low $T R$ will lead to great practical challenges regarding losses management at the absorber cavity and at the PCM container. Therefore an extra trade-off must be considered when designing practical systems.

\subsection{Examples of system configurations}

In this final section we present a detailed description of several system configurations according to the results shown in the previous sections. They are shown in Table 3. In all the cases, the system is operated close to the $M R=1$ critical line, that's why the emitter temperature is close to the melting temperature of Silicon $(1680 \mathrm{~K})$. From this table, we confirm that large PCM lengths require high $A R$ and low $T R$ to maximize the efficiency. Besides, we observe that the TPV efficiency is almost constant for all the configurations, while the absorber efficiency strongly depends on the configuration parameters. This is due to the almost constant emitter temperature for all of the designs. As a consequence, the optimum bandgap energy of the PV cells is in a narrow range of values $(0.481$ $0.526)$. This has the great benefit that regardless of the geometrical configuration choices, the same type of PV cells will maximize the conversion efficiency. However, it is important to note that the type of PV cell (bandgap energy) that maximizes efficiency is tied to the melting temperature of the PCM and to the BSR reflectivity value (i.e. quality of the TPV cavity recirculation system). Therefore, future studies will need to be conducted to identify the influence of the choice of PCM material and BSR on the PV cell choice.

Another interesting parameter listed in Table 3 is the electrical power density $\left(P_{E L}\right)$. This is defined by Eq. (12) as the delivered electrical power divided by the semicon- ductor PV cell area. Therefore, a high value is desirable to reduce the cost of the system. We see that in these system configurations, the power density is in the range of 10 $14 \mathrm{~W} / \mathrm{cm}^{2}$, which is more than 500 times the power density of conventional flat-plate PV cells $\left(\sim 0.02 \mathrm{~W} / \mathrm{cm}^{2}\right)$ and half of the power density of current triple junction cells within Concentrating-PV systems $\left(\sim 30 \mathrm{~W} / \mathrm{cm}^{2}\right)$.

Table 3 presents the mass of PCM per unit inlet hole area $\left(M_{P C M} / A_{h}\right)$ and an estimation of the lower limit of the solidification time of the PCM after sunset $\left(t_{\text {sol }}^{(L L)}\right)$. The former value $\left(M_{P C M} / A_{h}\right)$ has been calculated taking into account that $M_{P C M}=\rho_{S i} V_{P C M}$ where $\rho_{S i}$ the Silicon density $\left(2.33 \mathrm{~g} / \mathrm{cm}^{3}\right)$ and $V_{P C M}=A_{a} L(1+T R+\sqrt{T R})$ is the volume of the entire PCM, calculated by integration of Eq. (6). The latter value $\left(t_{\text {sol }}^{(L L)}\right)$ has been calculated assuming that the absorber is completely insulated during the solidification of the PCM (using, for instance, a highly reflective shutter on top of the inlet filter) and assuming a constant efficiency and electrical power density all through the solidification process. This last assumption results in the following energy balance equation: $t_{\text {sol }}^{(L L)} F_{e c} A_{e} P_{d}=L_{f} \rho_{S i} V_{P C M} M R \times \eta_{T P V}$, where $L_{f}$ the latent heat of fusion of Silicon $(1800 \mathrm{~J} / \mathrm{g})$. The resultant $t_{\text {sol }}^{(L L)}$ (shown in Table 3) can be considered as a lower limit for the actual solidification time $\left(t_{\text {sol }}\right)$ because the rate of energy extraction from the PCM will actually diminish in time, decelerating the solidification process. The running time after sunset $\left(t_{\text {run }}\right)$ should also take into account that the produced electrical power during the last part of the solidification process will be negligible due to the very low emitter temperature and conversion efficiency, so that $t_{\text {run }}<t_{\text {sol }}$. Therefore, $t_{\text {sol }}$ is the upper limit of the running time in that sense. Due to these uncertainties, we want to emphasize that the values of $t_{s o l}^{(L L)}$ given in Table 3 serve to give an approximate estimate of the expected running times after sunset. More accurate calculations of the transient process will be done in subsequent work.

Table 3 shows that very long running times (exceeding $10 \mathrm{~h}$ ) are plausible. Also, it is seen that the longest times are expected for large PCM length $(L)$ and $A R$ and low $T R$. Importantly, these long running times are possible with a very low amounts of Silicon, less than $2 \mathrm{~kg}$ per $\mathrm{cm}^{2}$ of inlet hole area, due to its extremely high latent heat of fusion. 


\section{Conclusions}

In this paper we have proposed a novel SISTPV system configuration for the conversion and storage of the solar energy. SISTPV systems are aimed at reducing the cost of conventional CSP systems, mainly due to their modularity and simplicity. We have seen that in the simplest configuration, they can approach $35 \%$ conversion efficiency and provide a very high electrical power density of $\sim 14 \mathrm{~W} / \mathrm{cm}^{2}$. Using Silicon as the PCM allows exploiting its very high latent heat of fusion of $1800 \mathrm{~kJ} / \mathrm{kg}$, which is one order of magnitude greater than conventional PCMs like molten salts, for heat storage. Importantly, these systems neither require any working fluid nor moving parts to convert heat into electricity, which potentially minimizes both the system and the maintenance costs.

In this paper, we have presented a simplified model for the full system in order to provide the first estimate of the system performance. Some of the main assumptions taken are: idealized PV cells (radiative limit) and one dimensional purely conductive (i.e. non-convective) heat transfer within the PCM. The theoretical equations that model the system have been solved and a parametric analysis has been conducted in order to find the optimum configuration that maximizes conversion efficiency and storage energy density simultaneously. We found that in order to maximize the system efficiency and ensure the highest storage energy density for a given PCM length, we should operate the system at the highest possible concentration and then, tune the configuration parameters $(T R$ and $A R$ ) so that the emitter temperature approaches the melting temperature of the Silicon PCM $(1680 \mathrm{~K})$. Higher system efficiencies would be possible if the emitter were operated at slightly lower temperatures than the Silicon melting point, but it comes at the expense of a lower storage energy density. Among all the combinations of $A R$ and $T R$ that allow meeting this condition, the arrangements with high $A R$ and low $T R$ will provide higher theoretical efficiencies and importantly, will allow using longer PCM lengths, which implies higher thermal energy storage capacity. In all of the cases, the use of a spectrally selective filter at the inlet absorber hole has been proved to be particularly important. This is because it improves the net energy transfer from the absorber to the PV cells, by tuning down the absorber emission losses. Finally, we have found that for the particular elected value of the BSR reflectivity of 0.9 , the optimum bandgap energy is about $0.5 \mathrm{eV}$, regardless of the geometrical configuration choices. To build cells with such low bandgap energy, a promising approach can be the deposition of thin quaternary InAsGaSb compounds on highly reflective substrates. Preliminary calculations of the transient performance indicate that running times after sunset above $10 \mathrm{~h}$ are possible. Importantly, long running times are possible with a very low amount of Silicon due to its very high latent heat of fusion.

Future research will focus on exploring the effects of convective motion of Silicon within the PCM container and designing the storage tank based on a transient analysis to achieve a required duration after sunset operation. Convective effects within the PCM are expected to enhance the heat transfer; thus, providing better system performance. Other improvements, such us the use of spectrally tailored emitters, multijunction PV cells or heat pumps / fins within the PCM will be also considered in subsequent works.

\section{References}

Andreev, V.M., Vlasov, A.S., Khvostikov, V.P., Khvostikova, O.A., Gazaryan, P.Y. Sadchikov, N.A., Rumyantsev, V.D., Loffe, A.F., 2006. Solar thermophotovoltaic converter with Fresnel lens and $\mathrm{GaSb}$ cells. In: Conference Record of the 2006 IEEE 4th World Conference on Photovoltaic Energy Conversion, 2006, pp. 644-647.

Andreev, V.M., Vlasov, A.S., Khvostikov, V.P., Khvostikova, O.A., Gazaryan, P.Y., Sorokina, S.V., Sadchikov, N.A., 2007. Solar thermophotovoltaic converters based on tungsten emitters. Journal of Solar Energy Engineering 129, 298-303.

Antón, I., Silva, D., Sala, G., Bett, A.W., Siefer, G., Luque-Heredia, I., Trebst, T., 2007. The PV-FIBRE concentrator: a system for indoor operation of $1000 \mathrm{X}$ MJ solar cells. Progress in Photovoltaics: Research and Applications 15 (5), 431-447.

Araújo, G.L., Martí, A., 1994. Absolute limiting efficiencies for photovoltaic energy conversion. Solar Energy Materials and Solar Cells 33, $213-240$.

Ardani, K., Margolis, R., 2010. Solar technologies market report. US Department of Energy. November 2011.

Arnaoutakis, G.E., Marques-Hueso, J., Mallick, T.K., Richards, B.S., 2013. Coupling of sunlight into optical fibres and spectral dependence for solar energy applications. Solar energy 93, 235-243.

Badescu, V., 2005. Upper bounds for solar thermophotovoltaic efficiency. Renewable Energy 30 (2), 211-225.

Bailey, J.M., 2010. Modelling Phase Change Material Thermal Storage Systems. McMaster University, Hamilton, Ontario, Canada.

Barlev, D., Vidu, R., Stroeve, P., 2011. Innovation in concentrated solar power. Solar Enegy Materials and Solar Cells 95, 2703-2725.

Basu, S., Zhang, Z.M., Fu, C.J., 2009. Review of near-field thermal radiation and its application to energy conversion. International Journal of Energy Research 33 (13), 1203-1232.

Bauer, T., 2011. Thermophotovoltaics: Basic Principles and Critiical Aspects of System Design. Springer, Berlin.

Bell, R.L., 1979. Concentration ratio and efficiency in thermophotovoltaics. Solar Energy 23 (3), 203-210.

Chubb, D.L., 2007. Fundamentals of thermophotovoltaic energy conversion. Elsevier.

Chubb, D.L., Good, B.S., Lowe, R.A. 1995. Solar thermophotovoltaic (STPV) system with thermal energy storage. In: 2nd NREL Conference on Thermophotovoltaic Generation of Electricity, 1995, pp. 181198.

Coutts, T.J., 1999. A review of progress in thermophotovoltaic generation of electricity. Renewable and Suitable Energy Reviews 3, 77-184.

Datas, A., 2011. Development of Solar Thermophotovoltaic Systems. Universidad Politécnica de Madrid, Madrid, Spain.

Datas, A., Algora, C., 2010. Detailed balance analysis of solar thermophotovoltaic systems made up of single junction photovoltaic cells and broadband thermal emitters. Solar Energy Materials and Solar Cells 94 (12), 2137-2147.

Datas, A., Algora, C., 2012a. Development and experimental evaluation of a complete solar thermophotovoltaic system. In: Progress in Photovoltaics: Research and Applications, 2012. (vol. published online). http://dx.doi.org/10.1002/pip.2201.

Datas, A., Algora, C., 2012b. Global optimization of solar thermophotovoltaic systems. In: Progress in Photovoltaics: Research and Applica- 
tions, 2012. (vol. published online). http://dx.doi.org/10.1002/ pip. 2202.

Davies, P.A., Luque, A., 1994. Solar thermophotovoltaics - brief review and new look. Solar Energy Materials and Solar Cells 37 (1), 11-22.

Edenburn, M.W., 1980. Analytical evaluation of a solar thermophotovoltaic (TPV) converter. Solar Energy 24 (4), 367-371.

Harder, N.-P., Würfel, P., 2003. Theoretical limits of thermophotovoltaic solar energy conversion. Semiconductor Science and Technology 18, S151-S157.

Horne, E., 2002. Hybrid thermophotovoltaic Power Systems. EDTECK, Inc.

Hsieh, C.K., 1995. Exact solutions of Stefan problems for a heat front moving at constant velocity in a quasi-steady state. International Journal of Heat and Mass Transfer 38, 71-79.

Huang, R.K., Wang, C.A., Connors,M.K., Turne, G.W., Dashiell, M., 2004. Hybrid back surface reflector GaInAsSb thermophotovoltaic devices, US Department of Energy, June 2004.

Huang, M.J., Eames, P.C., Norton, B., 2007. Comparison of predictions made using a new 3D phase change material thermal control model with experimental measurements and predictions made using a validated 2D model. Heat Transfer Engineering 28 (1), 31-37.

Huang, M.J., Eames, P.C., Norton, B., Hewitt, N.J., 2011. Natural convection in an internally finned phase change material heatsink for the thermal management of photovoltaics. Solar Energy Materials and Solar Cells 95, 1598-1603.

Ismail, K.A.R., Melo, C.A., 1998. Convection-based model for a PCM vertical storage unit. International Journal of Energy Research 22 (14), $1249-1265$.

Kennedy, C.E., 2002. Review of mid-to high-temperature solar selective absorber materials, NREL, July 2002.

Kreith, F., 2000. The CRC Handbook of Thermal Engineering. CRC Press, US.

Lagarias, J., Reeds, J., Wright, M., Wright, P., Dec. 1998. Convergence properties of the Nelder-Mead simplex method in low dimensions. Siam Journal on Optimization 9 (1), 112-147.

Lamberg, P., Siren, K., 2003. Analytical model for melting in a semiinfinite PCM storage with an internal fin. Heat and Mass Transfer 39, $167-176$.

Luque, A., Hegedus, S., 2003. Handbook of Photovoltaic Science and Engineering. Wiley.

Naaktgeboren, C., 2007. The zero-phase Stefan problem. International Journal of Heat and Mass Transfer 50, 4614-4622.

Nakamura, S., Hibiya, T., 1992. Thermophysical properties data on molten semiconductors. International Journal of Thermophysics 13 (6), 1061-1084.

Olivares, R.I., 2012. The thermal stability of molten nitrite/nitrates salt for solar thermal energy storage in different atmospheres. Solar Energy 86 (9), 2576-2583.

Shackelford, J.F., Alexander, W., 2001. Materials Science and Engineering Handbook third ed. CRC Press.

Shockley, W., Queisser, H.J., 1961. Detailed balance limit of efficiency of $p-n$ junction solar cells. Journal of Applied Physics 32, 510-519.

Stone, K.W., Leingang, EF., Kusek, S.M.,1994. On-sun test results of McDonnell Douglas' prototype solar thermophotovoltaic power system. In: 1994 IEEE 1st World Conference on Photovoltaic Energy Conversion - 24th IEEE Photovoltaic Specialists Conference, 1994, pp. 2010-2013.

Stone, K.W., Leingang, E.F., Drubka, R.E., 1994. Solar thermophotovoltaic power experiments at medonnell-douglas. In: 29 th Intersociety Energy Conversion, Engineering Conference, 1994, pp. 1692-1696.

Stone, K.W., Leingang, E.F., Drubka, R.E., 1994. Test results from a solar thermophotovoltaic power experiment. In: Proceedings of the American Solar Energy Society Annual Conference, 1994, pp. 174 178.

Stone, K.W., Kusek, S.M., Drubka, R.E., 1994. Analysis of solar thermophotovoltaic test data from experiments performed at McDonnell-Douglas. In: 1st NREL Conference on Thermophotovoltaic Generation of Electricity, 1994, pp. 153-162.

Stone, K.W., Leingang, E.F., Drubka, R.E., 1995. System performance of a solar thermophotovoltaic system for space and terrestrial application. In: 30th Intersociety Energy Conversion Engineering Conference - Energy Technologies for a Sustainable Future (IECEC 95), 1995, pp. A713-A718.

Stone, K.W., Chubb, D.L., Wilt, D.M., 1995. Testing and modeling of a solar thermophotovoltaic power system. In: 2nd NREL Conference on Thermophotovoltaic Generation of Electricity, 1995, pp. 199-209.

Stone, K.W., Fatemi, N.S., Garverick, L.M., 1996. Operation and component testing of a solar thermophotovoltaic power system. In: 25th IEEE Photovoltaic Specialists Conference, 1996, pp. 1421-1424.

Stone, K.W., Drubka, R.E., Kusek, S.M., Douglas, M.1996. A space solar thermophotovoltaic power system. In: 31st Intersociety Energy Conversion Engineering Conference (IECEC 96), 1996, pp. 1001-1006.

Sunshot Vision Study. US Dept Energy. February 2012.

Tobler, W.J., Durisch, W., 2008. High-performance selective er-doped YAG emitters for thermophotovoltaics. Applied Energy 85 (6), $483-$ 493.

Verma, P., Varun, Singal, S.K, 2008. Review of mathematical modeling on latent heat thermal energy storage systems using phase-change material. Renewable and Sustainable Energy Reviews 12, 999-1031.

Vlasov, A.S., Khvostikov, V.P., Khvostikova, O.A., Gazaryan, P.Y., Sorokina, S.V., Andreev, V.M., 2006. TPV systems with solar powered tungsten emitters. In: 7th World Conference on Thermophotovoltaic Generation of Electricity, Madrid, Spain 890, 327-334.

Wernsman, B., Siergiej, R.R., Link, S.D., Mahorter, R.G., Palmisiano, M.N., Schultz, R.W., Schmuck, G.P., Messham, R.L., Murray, S., Murray, C.S., Newman, F., Taylor, D., DePoy, D.M., Rahmlow, T., 2004. Greater than $20 \%$ radiant heat conversion efficiency of a thermophotovoltaic radiator/module system using reflective spectral control. IEEE Transactions on Electron Devices 51 (3), 512-515.

Wilt, D., Wehrer, R., Palmisiano, M., Wanlass, M., Murray, C., 2003. Monolithic interconnected modules (MIMs) for thermophotovoltaic energy conversion. Semiconductor Science and Technology 18 (5), pp. PII S0268-1242(03)60134-3.

Wojtczuk, S., 1997. Comparison of $0.55 \mathrm{eV}$ InGaAs single-junction vs. multi-junction TPV technology. In: Presented at the Third NREL Conference on Thermophotovoltaic Generation of Electricity, vol. 401, Colorado Springs, Colorado (USA), 1997, pp. 205-213. 